\title{
Phytochemical Screening of a Pandanus Species from Ando Island, Borongan City, Philippines
}

\author{
Neil Alejandro A. Pinarok ${ }^{1}$, Mila B. Casillano', Rey Niel C. Salac ${ }^{2}$ and Aljon Victor G. Nibalvos² \\ 'Graduate School, Eastern Samar State University, Borongan City, Eastern Samar, Philippines; \\ napinarok@yahoo.com, milacasillano@yahoo.com \\ ${ }^{2}$ College of Arts and Sciences, Eastern Samar State University, Borongan City, Eastern Samar, Philippines; \\ salacreyniel@gmail.com, aljonvictorgalitnibalvos@gmail.com
}

\begin{abstract}
Objectives: An endemic species of Pandanus found in Ando Island Borongan City was subjected to phytochemical analysis to verify presence of some secondary metabolites products by the plant sample. Methods: Qualitative analysis was used in phytochemical testing and color, odor and miscibility testing, while Quantitative analysis was used in $\mathrm{pH}$, boiling point and density of four (4) different types of extracts namely; Dried Leaves (DLE); Dried Fruit (DFE); Fresh Leaves (FLE); and Fresh Fruit (FFE) in determining the extracts' physical and chemical properties. Results: Results showed that the color of most plant extracts ranges from brown to dark brownish-green, strong odor, a density range from 0.77 to $0.87 \mathrm{~g} / \mathrm{cc}$. All extracts are basic and a boiling point range of 92.7 to $102.7{ }^{\circ}$ C. Moreover, all extracts are soluble to polar solvents, but insoluble to non-polar solvent. Phytochemical screening found out that alkaloid is present only on the fruit extract; saponin, steroid, and terpenoid are found to be positive, while tannin was found negative in all extracts. Flavonoid is present in FFE while glycoside is present only on Dried Fruit Extract (DFE). Improvements: It is hereby suggested that a quantitative analysis be carried out on the present secondary metabolites to determine if there is a new type of naturally-occurring compound present in the fruits or leaves of the Pandanus species and perform phytochemical analysis to other parts of the plant such as roots, bark, trunk, etc.
\end{abstract}

Keywords: Extracts Phytochemical Analysis, Pandanus, Secondary Metabolites

\section{Introduction}

In the recent years, plant-derived substances have been a center of interest for most researchers and scientists because of its diverse applications in the many fields of science more especially in medicine and pharmaceuticals. The first step for determining the kind and how it will be used of plant substances is to test for its phytochemical components or secondary metabolites.

Plants are source of large amounts of drugs comprising to different groups antispasmodics, emetics, anti-cancer, and antimicrobial and even as anti-HIV ${ }^{1}$.

Furthermore, medicinal plants are the richest bioresource of drugs of which are used in traditional systems of medicine, in modern medicines, neutraceuticals, food supplements, folk medicines pharmaceutical intermediates, and chemical entities for the replication and synthesis of laboratory-made drugs 2 .

Plant secondary metabolites are substances produced by plants during secondary metabolism other than photosynthesis. This process produces diverse amounts of specialized compounds which has a minimum impact on the growth and development of the plant itself, but these compounds are needed for the survival in different forms of environment. Hence, most floras confer different concentrations and presence of secondary metabolites when they thrive in a different environment.

Moreover, with the number of newer species of plant being discovered, it is more likely that these kinds of flora can give way to more potent antimicrobial or antiviral

${ }^{*}$ Author for correspondence 
substances or secondary metabolites. One species which was found to be endemic is the Pandanus sp.

Pandanus is a genus of monocots with some 750 accepted species. They are palm-like, dioecious trees and shrubs native to the Old World tropics and subtropics ${ }^{3}$. A recent Pandanus species was found in Ando Island by the researchers which enable the interest of the same to have the first step in determining its chemical characteristics, determination of its present phytochemicals.

\section{Objectives of the Study}

This study was conducted to determine the presence of alkaloid, anthraquinone, flavonoid, glycoside, saponin, steroid, and tannin and terpenoid secondary metabolites in the Pandanus sample. Also, this study determined the percent yield of extract of the Pandanus sp.; determined the physical properties of the leaves and fruit extract of the Pandanus species in terms of: (a) boiling point, (b) color, (c) density, (d) solubility/miscibility, (e) odor, and (f) $\mathrm{pH}$; and lastly, this study determined the difference in the presence of secondary metabolites in the fruit and leaves, and also in terms of being fresh and dried.

\section{Methodology}

\subsection{Research Design}

This study made use of the Experimental Research Design utilizing qualitative and quantitative methods of testing to determine the physical properties and the present secondary metabolites in the fruit and leaves of the Pandanus sp.

Qualitative analysis-type of research design was used in identifying the presence of phytochemicals. All tests were done in triplications. Testing was done at Eastern Samar State University, Chemistry Laboratory.

\section{Data Gathering Procedures}

\subsection{Collection and Preparation of}

\section{Pandanussp. Sample}

One (1) unripe fruit sample and 1 kilogram of leaves of Pandanus were collected from Ando Island. The said samples were then brought into the Laboratory which was subjected to tap and distilled water to clear out dirt and unwanted particulates. After cleaning, four (4) sets of samples were produced: a fresh and dried sample of fruit and a fresh and dried sample of leaves. Maceration and Digestion methods were used in extracting the fruit and leaves samples.

Approximately 100 - $150 \mathrm{~g}$ of fresh and dried fruit and leaves were chopped to fine pieces and was submerged in alcohol solvent in separate Erlenmeyer flasks for extraction at a period of 7 days with constant agitation. After the period, the extract-solvent solutions were heated until the alcohol solvent evaporates. The remaining extracts of each prepared dried and fresh fruit and leaves were then subjected to physical property testing and phytochemical analysis.

\subsection{Percent Yield}

The following equation was utilized to determine the percent yield of the samples:

Triplication was done on percent yield and average was determined.

\section{Physical Properties Determination}

\subsection{Boiling Point}

$5 \mathrm{~g}$ equivalent of the semi-solid extract was put into a macro test tube; the test tube was then submerged into an oil bath. Afterwards, the oil bath was heated until the sample extract starts to boil. The unvarying temperature at which the sample extract boils for 30 seconds was recorded.

\subsection{Color and Odor}

Color and Odor determination was done by the efforts of five (5) random respondents who assessed using their sense of sight and olfactory sense, respectively. The perceived color and odor of the respondents was recorded and tabulated.

\subsection{Density}

Density was determined by taking the displacement of a $2 \mathrm{~g}$ sample extract of sample extract. The volume of displacement was recorded and the density was determined by computing with the following equation: 


\subsection{Solubility}

In this test, five (5) solvents were used as solvents to determine the solubility of the crude extracts. About $1 \mathrm{~g}$ or $\mathrm{mL}$ equivalent of sample was added to $4 \mathrm{~mL}$ of solvent. The results were recorded.

\section{$5.5 \mathrm{pH}$}

The $\mathrm{pH}$ of the sample extracts was determined by using a digital $\mathrm{pH}$ meter and the readings were recorded.

\subsection{Phytochemical Screening}

Phytochemical screening was done to both fresh and dried sample extracts in three (3) trials. Phytochemical testing was done in which the crude extract was at its semi-solid state.

\subsection{Alkaloid}

Preliminary and Confirmatory tests were done to determine alkaloids presence in the all samples.

\subsubsection{Preliminary Testing}

Plant extract was put into an evaporating dish and evaporated to a syrupy consistency over a steam bath. $5 \mathrm{~mL}$ of $2 \mathrm{M} \mathrm{HCl}$ solution was added with stirring over a hot plate for 5 minutes and cooled. Afterwards, $0.5 \mathrm{~g}$ of $\mathrm{NaCl}$ was added, stirred and filtered. The residue was then added with enough $2 \mathrm{M} \mathrm{HCl}$ to bring the filtrate to about $5 \mathrm{~mL}$. The samples were divided into three test tubes with $3 \mathrm{~mL}$ : $1 \mathrm{~mL}: 1 \mathrm{~mL}$ ratio.. The first $1 \mathrm{~mL}$ filtrates was tested with 2 to 3 drops of Dragendorff's reagent, and the other was tested with 2 drops of Mayer's reagent ${ }^{4}$.

The relative amount of precipitation was observed as follows: (+) slight turbidity; (++) definite turbidity; $(+++)$ heavy turbidity.

All samples with turbidity were subjected to confirmatory tests for alkaloids.

\subsubsection{Confirmatory Testing}

The remaining $3 \mathrm{~mL}$ of the filtrate (from Preliminary Test) was added with 2 drops of $28 \%$ Ammonia until the solution is alkaline. Next, the alkaline solution was extracted three times with small portions of chloroform (not less than $10 \mathrm{~mL}$ ). The lower chloroform extracts was then combined while the upper aqueous layer was reserved.
The chloroform extract was allowed to evaporate to dryness over a steam bath and the residue was taken up with $5 \mathrm{~mL}$ of $2 \mathrm{M} \mathrm{HCl}$ and stirred over the steam bath for 2 minutes. Next, it was filtered and divided into two portions. The first portion was tested again 2 to 3 drops of Dragendorff's reagent, and the other was tested with 2 drops of Mayer's reagent. Turbidity in the tube indicates the presence of primary, secondary and tertiary alkaloids.

\subsection{Anthraquinone}

Plant extract was evaporated to dryness over a steam bath. Then, the residue was added with distilled water and filtered. The filtrate was then extracted twice with Benzene, and then the portions were combined. The combined benzene extracts was then divided into two portions. One portion was used as control while the other portion was treated with ammonia and shaken. It was then compared to the control tube and the presence of red coloration in the lower ammoniacal layer indicates the presence of anthraquinones.

\subsection{Flavonoid}

Plant extract was evaporated to incipient dryness over a steam bath. It was cooled to room temperature and then after cooling, it was defatted by taking up the residue with Petroleum ether. The petroleum ether extract was discarded.

The defatted aqueous layer was then diluted with 10 $\mathrm{mL}$ of $80 \%$ ethanol. It was divided into four test tubes. One test tube was reserved as control. The other 3 remaining tubes were treated with $80 \%$ ethanol and $0.5 \mathrm{~mL}$ of concentrated $\mathrm{HCl}$. It was then observed for apparent color change. Next, the tubes were warmed in water bath and further observed for color changes within the next hour and compared with the control. Strong violet or red color indicates the presence of Leucoanthocyanin.

\subsection{Glycoside}

Gram equivalent of plant extract was put into a test tube, and then it was added with enough water to moisten the extract and 5 drops of chloroform to enhance enzyme activity of the extract. Then, the tube was stoppered with a cork from which a picrate paper (a filter paper submerged in sodium picrate solution and dried) is suspended, making sure that the paper does not touch the inner sides of 
the test tube. The test tube was then warmed in a water bath and was observed for any color change in the picrate paper. Appearance of various shades of red within 15 minutes when the tube is warmed indicates the presence of cyanogenic glycoside.

\subsection{Saponin}

Plant extracts were diluted with distilled water and shaken in a graduated cylinder. Formation of $1 \mathrm{~cm}$ layer of foam indicates the presence of saponin.

\subsection{Steroid}

Plant extract was evaporated to dryness over a steam bath. Afterwards, it was cooled to room temperature. Next, it was defatted by taking up the residue with $6 \mathrm{~mL}$ of Hexane and Water $(2: 1 \mathrm{v} / \mathrm{v})$. Partition the mixture by gently shaking the test tube and pipette out the hexane layer. The treatment was repeated until most of the colored pigments have been removed. The hexane extract was discarded. Then, the defatted aqueous solution was heated in a water bath to remove excess Hexane and cooled at room temperature. The cooled solution was then divided into three (3) portions. All portions were tested using Liebermann-Burchard test for Unsaturated Steroids.

One portion of the defatted layer was added with 10 $\mathrm{mL}$ of Dichloromethane and stirred for a few minutes and allowed to stand. Afterwards the lower DCM extract was pipetted and dried by passing the DCM extract into $2 \mathrm{~g}$ of anhydrous sodium sulfate placed over a dry filter paper in a funnel. The filtrate was then divided as control and as sample which was then treated with 3 drops of acetic anhydride and one drop of concentrated Sulfuric acid. It was then observed for immediate color change. If no change is observed it was subjected to standing for 1 hour for further change in color and compared with the control. A positive result gives colors ranging from blue,

Table 1. Summary table of the pandanus physical and phytochemical analysis

\begin{tabular}{|c|c|c|c|c|}
\hline Properties & FFE & DFE & FLE & DLE \\
\hline Percent Yield (\%) & 69.5 & 53.7 & 59.1 & 74.2 \\
\hline Color & Brown & $\begin{array}{l}\text { Dark } \\
\text { Brown }\end{array}$ & Dark Green & Brownish-green \\
\hline Odor & Strong Odor & $\begin{array}{l}\text { Strong } \\
\text { Odor }\end{array}$ & Unpleasant & Strong Unpleasant \\
\hline Density (g/cc) & 0.83 & 0.87 & 0.77 & 0.77 \\
\hline $\mathrm{pH}$ & 8.52 & 8.24 & 7.12 & 7.39 \\
\hline Boiling Point $\left({ }^{\circ} \mathrm{C}\right)$ & 102.7 & 100.7 & 98.7 & 92.7 \\
\hline \multicolumn{5}{|l|}{ Solubility to: } \\
\hline Water & Soluble & Soluble & Soluble & Soluble \\
\hline Chloroform & Insoluble & Insoluble & Insoluble & Slightly Soluble \\
\hline Alcohol & Soluble & Soluble & Soluble & Soluble \\
\hline $5 \% \mathrm{HCl}$ & Soluble & Soluble & Soluble & Soluble \\
\hline $5 \% \mathrm{NaOH}$ & Soluble & Soluble & Soluble & Soluble \\
\hline \multicolumn{5}{|c|}{ Phytochemical Analysis } \\
\hline Alkaloid & $\mathrm{P}$ & $\mathrm{N}$ & $\mathrm{N}$ & $\mathrm{N}$ \\
\hline Anthraquinone & $\mathrm{P}$ & $\mathrm{P}$ & $\mathrm{P}$ & $\mathrm{P}$ \\
\hline Flavonoid & $\mathrm{P}$ & $\mathrm{N}$ & $\mathrm{N}$ & $\mathrm{N}$ \\
\hline Glycoside & $\mathrm{N}$ & $\mathrm{P}$ & $\mathrm{N}$ & $\mathrm{N}$ \\
\hline Saponin & $\mathrm{P}$ & $\mathrm{P}$ & $\mathrm{P}$ & $\mathrm{P}$ \\
\hline Steroid & $\mathrm{P}$ & $\mathrm{P}$ & $\mathrm{P}$ & $\mathrm{P}$ \\
\hline Tannin & $\mathrm{N}$ & $\mathrm{N}$ & $\mathrm{N}$ & $\mathrm{N}$ \\
\hline Terpenoid & $\mathrm{P}$ & $\mathrm{P}$ & $\mathrm{P}$ & $\mathrm{P}$ \\
\hline
\end{tabular}

Legend: $\mathrm{P}$ - positive result; $\mathrm{N}$ - negative result 
green, red, pink, purple or violet due to the steroid/triterpenoid skeleton.

\subsection{Tannin}

Plant extract was incipiently dried over a steam bath and the residue was extracted with hot distilled water and added with $\mathrm{NaCl}$ solution. It was filtered and the filtrate treated with gelatin-salt reagent. Formation of a jelly white precipitate indicates the presence of tannins.

\subsection{Terpenoid}

Plant extract was evaporated to incipient dryness over a steam bath and cooled to room temperature. It was then defatted the taking up the residue with $6 \mathrm{~mL}$ of Hexane and Water (2:1 v/v). Partition the mixture by gently shaking the test tube and pipette out the hexane layer. The treatment was repeated until most of the colored pigments have been removed. The hexane extract was discarded. The aqueous layer was then treated with $10 \mathrm{~mL}$ Chloroform and gently shaken. It was allowed to stand and the chloroform extract was pipetted off. The Chloroform extract was then dried by filtering the mixture through $2 \mathrm{~g}$ of anhydrous sodium sulfate held by a filter paper in a funnel. The filtrate was divided into two; one served as control and the other was treated with 3 drops of acetic anhydride and 1 drop of concentrated sulfuric acid. It was observed for immediate color change and let stand for one hour for further color development. A positive result is indicated by colors blue, green, red, pink, purple or violet in the extract. Compare with the control.

\section{Results}

After several laboratory tests and analysis, the following data were obtained in the conduct of this study. After extraction, a semi-solid extracts were obtained from four (4) prepared plant samples as shown in Table 1.

\section{Discussion}

It can be observed from the data above that all the plant samples have higher than $50 \%$ percent yield which indicates that the Pandanus species found in Ando island has more extracts that can be obtained using methanol. But in contrast, the percent yield obtained here might have some impurities. Also, in terms of color and odor, most of the respondents observed a color range from brown to dark green in all the samples. Moreover, most respondents observed an intense unpleasant odor in almost all the plant extracts. These are the results of the maceration and agitation of the plant samples when it was subjected to solvent during the process of extraction.

In terms of density, it can be observed that the semisolid extracts of all the samples have a lower density than that of water, in which case, dried leaves extracts and fresh leaves extracts have the same density.

$\mathrm{pH}$ of all the samples is basic, in which the $\mathrm{pH}$ ranges from 7.12 to 8.52 . This implies that the extracts of the Pandanus species has a basic nature. In terms of its solubility, all the plant samples are soluble water, alcohol, acid and base solutions, but is insoluble in organic substances which implies that the extract is polar in nature or has some polar substances found in it. Final physical property testing showed that the boiling point range of the samples from $92.7^{\circ} \mathrm{C}$ to $102.7^{\circ} \mathrm{C}$ implies that the pandanus plant extract has a high boiling point.

Phytochemical analysis revealed that, in the fruit extract only, regardless whether fresh or dried samples is that alkaloid is was found to be present in the fruit extract only and is not on its leaves. Anthraquinone was found to be positive in the fruit and in the leaves of the pandanus extract inferring that anthraquinone substances can be found in the fruit and leaves of the Pandanus species found in Ando Island, Borongan City.

Since flavonoid can be degraded by enzyme action when collected plant material is fresh or non-dried, this could be the reason why only in the fresh fruit extract, a positive result was obtained. This implies that flavonoid is not present in the pandanus found in Ando Island.

In terms of glycoside testing, only in the dried fruit extract a positive result was obtained implying that glycoside is absent on the leaves and fresh fruit of the endemic Pandanus species.

All test obtained a positive result for saponin in which case, fruit and leaves of the pandanus contain saponin considering that saponin is present in almost all plant in the world.

It is interesting to note that regardless whether fruits or leaves, the pandanus contain steroidal compounds, since only a small number of plant can contain diverse group of natural products known as steroids.

In terms of tannin analysis, no tannin-like compounds or substances were detected in both leaves and fruits, regardless whether fresh or dried. Implying that the 
pandanus found in Ando Island lacks tannin in its floral chemistry.

It is also noteworthy that in terpenoid test, all the samples obtained a positive result, indicating the presence of terpenoid compounds in both leaves and fruits of the endemic Pandanus species.

\section{Conclusions}

1. The percent yield of the fresh fruit extract, dried fruit extract, fresh leaves extract and dried leaves extract is $69.5 \%, 53.7 \%, 59.1 \%$ and $74.1 \%$, respectively. This implies that there is a high percent yield for all the samples in the crude extract form.

2. The fruit extracts has a higher boiling point that the leaves extract, regardless whether dried or fresh. The color of most extracts ranges from brown to dark green and brownish green. Its density is lesser than water in which FFE, DFE, FLE and DLE has a density of 0.83 , $0.87,0.77$ and 0.77 , respectively. All extracts are soluble to polar solvents but slightly soluble to insoluble to non-polar solvent, in which case Chloroform is the non-polar solvent. The respondents mostly observed a strong unpleasant odor due to the presence of alcoholic solvent. Lastly, the $\mathrm{pH}$ of all the extracts ranges from $7.12-8.52$ which signify that all the extracts are basic.

3. In the phytochemical screening, alkaloid was present only on the fresh fruit and dried fruit extracts, flavonoid was present only on the fresh fruit extract, anthraquinone, steroid, terpenoid and saponin was present to all the extracts, and glycoside was present only on the dried fruit extract. Tannin was found to be absent on all the prepared extracts.

4. It was found out that there is no difference in the presence of anthraquinone, steroid, terpenoid and saponin in both leaves and fruit. But in contrast, alkaloid and glycoside are found only in the fruit extract, the leaves do not contain these two secondary metabolites. Also, both plant parts do not contain tannin.

\section{Recommendations}

1. Perform quantitative analysis on the present secondary metabolites to determine if there is a new type of compound present in the fruits or leaves of the Pandanus species.

2. Perform another phytochemical screening involving other secondary metabolites.

3. Perform the same tests to further validate the results of this study.

4. Perform other phytochemical screening involving different types of solvents to maximize secondary metabolite extraction.

5. Perform phytochemical analysis to other plant parts such as roots, bark, trunk, etc.

\section{References}

1. Tiwari P, Kumar B, Kaur M, Kaur G, Kaur H. Phytochemical Screening and Extraction: A Review, Internationale Pharmaceutica Sciencia. 2011; 1(1):98-106.

2. Ncube NS, Afolayan AJ, Okoh AI. 2008. Assessment techniques of antimicrobial properties of natural compounds of plant origin: Current methods and future trends, African Journal of Biotechnology. 2008; 7(12):1797-806. https:// doi.org/10.5897/AJB07.613.

3. The Plant List. Dace Accessed: 11/04/2017. http://www.theplantlist.org/.

4. Guevara BQ. A guidebook to plant screening: phytochemical and biological. University of Santo Tomas: Philippines; 2005. p. 150. 